РЫЖОВА Светлана Валентиновна - кандидат социологических наук, ведущий научный сотрудник Института социологии Федерального научно-исследовательского иентра РАН (117218, Россия, г. Москва, ул. Кржижановского, 24/35, корп. 5; Silica2@yandex.ru)

\title{
О СОЦИОКУЛЬТУРНЫХ ОСНОВАНИЯХ РОССИЙСКОЙ ИДЕНТИЧНОСТИ
}

\begin{abstract}
Аннотация. В статье обобщаются результаты социологических исследований российской и этнической идентичностей. Автор приходит к выводу, что в условиях относительной слабости гражданских структур и политической культуры участия формирующаяся российская идентичность опирается на широкий круг социокультурных источников, в числе которых этническая идентичность, межэтническая толерантность и культура доверия. Эти компоненты образуют присоединяющий социальный капитал (bridging social capital, по P. Патнэму), направленный на вовлечение россиян в единое поле гражданской интеграции.
\end{abstract}

Ключевые слова: российская идентичность, этническая идентичность, доверие, межэтническая толерантность, социокультурные основания

B научных и общественно-политических кругах РФ широко дискутируются вопросы политической российской нации. Обсуждается характер гражданской идентичности россиян, ее структура, состав, содержательное наполнение [Горшков 2013; Дробижева 2018; Пантин 2011; Семененко 2015; Тишков 2008-2016]. Эксперты отмечают, что становление российской нации проходит несколько этапов, и наиболее отчетливым индикатором этих процессов является формирование интегрирующей российской идентичности. Большинство исследователей сходятся во мнении, что институциональное и мировоззренческое поле формирования российской идентичности находится в процессе активного становления. По мысли Л.Г. Бызова, процесс нациестроительства опирается на формирующийся в крупных городах России устойчивый средний класс и сопутствующие ему ценностно-нормативную унификацию, требования социальной справедливости и порядка [Бызов 2012].

Как любая социальная идентичность, российская идентичность имеет когнитивное, аффективное, поведенческое измерения. В широком понимании она включает в себя «ценности, установки, предпочтения», порождаемые

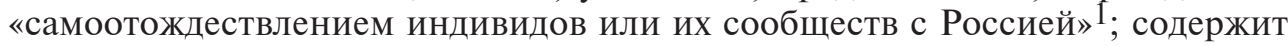
представления о государстве, обществе, стране, культуре, чувстве общности и гражданской ответственности [Дробижева 2018]; формируется «на основе комплекса политических, историко-культурных и морально-правовых характеристик» [Тишков 2008-2016: 34]. Ее роль особенно важна в условиях нарастающей глобализации [Горшков 2013]. По мнению Э. Паина и С. Федюнина, для успешного формирования российской идентичности необходимы действующие структуры гражданского общества и сопутствующая ему гражданская активность, которые складываются в условиях либеральной демократии [Паин, Федюнин 2018].

Согласно конструктивистским подходам, в российской идентичности, складывающейся на основе самоотождествления с категорией «граждане России», «россияне», первостепенное значение имеют усилия власти и элит, введение и широкое использование доктринальным дискурсом понятия «российская

\footnotetext{
1 Холодковский К.Г. 2017. Российская идентичность: исторический путь. - Идентичность: Личность, общество, политика: энциклопедическое издание (отв. ред. И.С. Семененко). М.: Весь Мир. С. 157-162.
} 
нация», «российская идентичность», его активное продвижение в обществе и закрепление в массовом сознании. Вместе с тем управленческий тренд может быть эффективным, если соединяется со стихийными процессами формирования идентичности. На повседневном уровне российская идентичность соотносится с чувством «мы», построенном на основе параметров, воспринимаемых большинством как стабильные и неизменные, - русского языка, культуры, в т.ч. праздничной и религиозной, разделяемых большинством ценностей и обычаев, норм повседневного взаимодействия. Как показывают исследования, о которых речь пойдет ниже, для этнического большинства страны базовым социокультурным параметром их российской идентичности выступает этническая (русская) идентичность.

Россия исторически сложилась как страна с высоким уровнем этнокультурного разнообразия, в советский период произошло закрепление этнического фактора на уровне социальных институтов. Поэтому зафиксированная в Стратегии государственной национальной политики цель формирования общегражданской российской идентичности призвана учитывать высокую значимость этничности для россиян. Результаты многолетних исследований Центра этнической социологии ФНИСЦ РАН широкого круга проблем, связанных с вопросами идентичности и межнационального согласия, позволяют заключить, что российская идентичность опирается на широкий круг социокультурных источников. Важную роль в их числе играют этничность и культура доверия.

Российская и этическая идентичности. Современные социальные макроидентичности - российская и этническая - являются комплексными, многоуровневыми и взаимозависимыми образованиями. Э. Смит показал на основе исторических исследований, что в формировании современных государственно-гражданских идентичностей активно задействованы элементы культуры и исторической памяти [Smith 1986]. Эти выводы британского историка справедливы и для России. На протяжении всего постсоветского развития страны этносоциологи фиксируют, что российская и этническая идентичности россиян разных национальностей не противоречат друг другу [Дробижева, Рыжова 2015].

Уровень российской и этнической идентичностей в России одинаково высок. Согласно данным всероссийского опроса ФАДН-ВЦИОМ 2019 г., $191 \%$ опрошенных в той или ной мере ощущают общность с гражданами России, при этом большинство (67\%) ощущают ее часто. Столь же велики показатели этнической идентичности - 94\% в той или иной мере ощущают общность с людьми своей национальности, при этом $74 \%$ обладают актуализированной этнической идентичностью, ощущая эту общность часто (см. табл. 1).

Подобная тенденция прослеживается и в регионах России. Согласно опросам 2014-2019 гг. 2, общий уровень как этнической, так и российской идентичности одинаково высок. Уровень этнической идентичности составляет $92 \%$ в

1 Общероссийский опрос, осуществленный ВЦИОМом по заказу ФАДН в ноябре 2019 г., $(N=2$ 000). Репрезентативная выборка строилась на основании данных Росстата (перепись населения за 2010 г.) и включает в себя 200 кластеров (точек отбора).

2 Репрезентативные социологические опросы Центра исследования межнациональных отношений ИС ФНИСЦ РАН в 2014-2018 гг. в областях и республиках РФ - Астраханской, Калининградской, Московской обл., Москве, Республике Карелия, Ставропольском крае. Использовалась территориальная, вероятностная, трехступенчатая случайная выборка $(N=1000-1200$ чел. в каждом регионе). В Татарстане опрос проводился совместно с РОО «Центр по изучению дискриминаций, экстремизма и ксенофобий Республики Татарстан» по общереспубликанской случайной стратифицированной выборке $(N=2000)$. 
Таблица 1

Уровень российской и этнической идентичности в РФ*, в \% от числа опрошенных

\begin{tabular}{|l|c|c|}
\hline \multicolumn{1}{|c|}{ Идентичности } & Российская & Этническая \\
\hline Степень переживания общности, близости... & $\begin{array}{c}\text { С гражданами } \\
\text { России }\end{array}$ & $\begin{array}{c}\text { С людьми своей } \\
\text { национальности }\end{array}$ \\
\hline Часто ощущают & 67 & 74 \\
\hline Иногда ощущают & 24 & 20 \\
\hline Никогда не ощущают & 5 & 4 \\
\hline Общий уровень идентичности & 91 & 94 \\
\hline
\end{tabular}

* По данным всероссийского опроса ФАДН-ВЦИОМ 2019 г.

Астраханской обл., 91\% в Калининградской обл., 90\% в Ставропольском крае, $89 \%$ в Карелии, $87 \%$ в Московской обл., $84 \%$ в Москве, $89 \%$ в Республике Татарстан. Уровень российской идентичности - 88\% в Астраханской обл., 91\% в Калининградской обл., 87\% в Ставропольском крае, $83 \%$ в Карелии, $84 \%$ в Москве, $84 \%$ в Московской обл., $85 \%$ в Республике Татарстан.

Будучи по функциям общегражданской, российская идентичность формируется сегодня как преимущественно государственно-гражданская, поскольку ведущим критерием ее становления, одинаково востребованным россиянами различных национальностей, является «общее государство» [Дробижева 2018]. Политическая культура участия в России пока развита слабо. Согласно данным Левада-Центра 2019 г., лишь $16 \%$ россиян чувствуют свою способность влиять на происходящее в их городе/районе, и $11 \%$ - на происходящее в стране (хотя чувствуют свою ответственность в этих сферах несколько больше - $21 \%$ и $29 \%$ соответственно); $21 \%$ опрошенных готовы лично активно участвовать в политике. При этом представление о социокультурных основах развития распространены значительно шире: доля сторонников особого пути развития России достигает $58 \% 1$. Поэтому в формирующейся российской идентичности заметно проявляют себя традиционные, дополитические основания интеграции, отражающие опыт самоорганизации и неконфликтного сосуществования в едином социальном пространстве России различных сообществ и культур.

Социологические исследования последних 25 лет $^{2}$, осуществленные в республиках, областях, мегаполисах РФ, позволяют говорить, что современная российская идентичность (и в первую очередь русских как этнического большинства страны) формируется с активной опорой на этническую (этнокультурную) идентичность. В процессах формирования российской идентичности широко задействованы эмоционально насыщенные основания этнической иденти-

\footnotetext{
1 Общественное мнение - 2019. М.: Левада-Центр, 2020. 188 с. Доступ: https://www.levada. $\mathrm{ru} / \mathrm{cp} / \mathrm{wp}$-content/uploads/2020/02/ОМ-2019.pdf (проверено 03.08.2020).

2 Использовался блок вопросов опросного листа, широко применяемых в этносоциологических исследованиях, нацеленных на исследование межэтнических установок, обнаружение культурных маркеров этнической идентичности, оценку межэтнических отношений и взаимодействий; использовался инструментарий, созданный группой В.А. Ядова, позволяющий оценить распространенность различных видов (этнической, российской) социальной идентичности и степень ее актуализации (выбор позиции «часто» и «в значительной степени» ощущаю близость, единство... с людьми данной группы/категории), адаптированная шкала социальной дистанции Е. Богардуса. Для демонстрации роли этнического фактора в социальных трансформациях и преобразованиях рассматривались политические и социальные установки этнических групп.
} 
фикации, такие как язык, общее историческое прошлое, элементы культуры, в т.ч. традиции и традиционные ценности, праздники и др. Эмоциональная вовлеченность и вдохновляющий импульс государственно-гражданской российской идентичности обеспечиваются и поддерживаются участием чувств, представлений, мотиваций, входящих в комплекс этнической (этнокультурной) идентичности. Связующим звеном между процессами усиления этнической идентичности и становления государственно-гражданской идентичности является установка межэтнической толерантности [Рыжова 2011], понимаемая, согласно Декларации ЮНЕСКО ${ }^{1}$, как принятие (в той или иной степени) культурного разнообразия социального пространства, отказ от применения насилия в урегулировании межэтнических и межконфессиональных конфликтов, взаимодействие на основе согласия или компромисса.

Если в советский период этническая толерантность базировалась на диффузной (субъективно не значимой) этнической идентичности (как русских, так и других национальностей СССР), то в постсоветское время ситуация принципиально изменилась: диффузная этническая идентичность россиян трансформировалась в субъективно значимую, когда большинство людей вовлекаются в процессы этнической категоризации и оценок.

Для русских их этническая солидарность выступает ресурсом для оптимистичного восприятия перспектив развития России. Русские, придерживающиеся мнения, что «в наше время человеку нужно ощущать себя частью своей национальности», демонстрируют более оптимистичное восприятие будущего страны; среди них выше лояльность российскому государству и обществу, любовь к России, приверженность идеям державного государства. Вовлекаясь в процессы формирования общероссийской идентичности, этническая солидарность русских поддерживает интегрирующие ориентации, складывающиеся на основе исторического опыта и духовных традиций [Российское общество... 2015].

Исследование ФАДН-ВЦИОМа 2019 г. подтверждает эту тенденцию: среди россиян с актуальной этнической идентичностью (часто чувствующих общность с людьми своей национальности) значимость российской идентичности (частое чувство общности с гражданами России) достигает 93\%. В условиях относительной слабости гражданских структур и политической культуры участия российская и этническая идентичности (главным образом русских как большинства страны) взаимно поддерживают и питают друг друга; формирующаяся российская идентичность в значительной мере использует эмоциональный, культурный, символический потенциал этнической идентичности.

Культура доверия. Доверие - это ключевой элемент социального капитала и активный источник гражданского развития и формирования гражданской идентичности [Putnam 2001; Фукуяма 2006]. Социологические исследования дают основание считать, что большой вклад в формирование общенационального гражданского единства способно внести обобщенное доверие (людям в целом) и «внеродственное доверие» (соседям, коллегам, друзьям), а также навыки межэтнической толерантности. Эти элементы образуют присоединяющий социокультурный капитал (bridging social capital, по Р. Патнэму), направленный на вовлечение всех граждан страны, независимо от их этнической, конфессиональной, региональной, статусной принадлежности, в единое поле гражданской интеграции. Понятие присоединяющего социального капитала

\footnotetext{
1 Декларация принципов толерантности. Утверждена резолюцией 5.61. Генеральной конференции ЮНЕСКО от 16 ноября 1995 г. Доступ: https://www.un.org/ru/documents/ decl_conv/declarations/toleranc.shtml (проверено 13.11.2020).
} 
позволяет комплексно изучать механизмы становления российской идентичности в условиях российской политической культуры и сложившихся институциональных форм этничности.

Сравнительный анализ исследований в упомянутых ранее российских регионах, характеризующихся различным социально-экономическим и политическим статусом, этнокультурной вариативностью, показал, что уровень обобщенного доверия ${ }^{1}$ (доверия к людям в целом) во всех регионах сходен и достаточно высок (42-48\%). Он не зависит от региона, не различается среди русского большинства и людей других национальностей, способствует межэтнической толерантности, что дает основание считать его одним из универсальных источников государственно-гражданской общероссийской консолидации и фактором сопутствующего ей межнационального согласия ${ }^{2}$ [Межнациональное согласие... 2016].

Формирующаяся в России культура доверия проявляется в том, что большинство россиян в исследованных регионах испытывают доверие к друзьям, коллегам и соседям. Как показали Р. Патнэм и Ф. Фукуяма, именно эти виды доверия становятся со временем основой для формирования широкого круга гражданских ассоциаций, построенных на «внеродственных» социальных связях. Уровни доверия коллегам и соседям варьируются по регионам: они ниже в Москве и Московской обл. (62-61\%) и выше в Астраханской и Калининградской обл. (77-73\%), Ставропольском крае и Карелии (71-80\%). Уровень доверия друзьям одинаково высок во всех регионах и колеблется около 90\%, что говорит о высоком потенциале гражданских коопераций разного уровня. Доверие соседям и коллегам, друзьям и знакомым является базисом дальнейшей социальной интеграции и тем фундаментом, на котором под влиянием благоприятных социально-экономических и политических факторов «надстраивается» обобщенное доверие.

Обобщенное доверие инициирует гражданскую активность [Фукуяма 2006], поэтому его уровень в известной мере определяет гражданский потенциал российской идентичности. Важный вывод исследований состоит в том, что обобщенное доверие во всех регионах благоприятствует формированию российской идентичности. Уровень актуализации российской идентичности («в значительной степени» ощущают себя гражданами России) составляет 57\% среди тех, кто доверяет людям в целом, и $39 \%$ среди тех, кто не доверяет (в Астраханской обл.). В Калининградской обл. это соотношение составляет $57 \%$ и 49\%, в Московской агломерации - 36\% и 22\%, в Ставропольском крае - $48 \%$ и $36 \%$, в Карелии - 40\% и 30\%, в Башкортостане - 31\% и 22\%, в Татарстане $50 \%$ и $42 \%$.

Среди людей, придерживающихся в своей жизни установок обобщенного доверия, возрастают ведущие показатели межэтнической толерантности. Так, в Астраханской обл. среди респондентов, готовых доверять людям в целом, 64\% никогда не чувствуют враждебность к людям других национальностей, а среди

\footnotetext{
1 Мы использовали простую 4-балльную шкалу, позволяющую выявить чистые установки обобщенного доверия/недоверия. При ответе на вопрос: «Как Вы считаете, можно ли доверять большинству людей?» - предлагались варианты ответов: «большинству людей точно можно доверять», «большинству людей скорее можно доверять», «большинству людей скорее нельзя доверять», «большинству людей точно нельзя доверять» [Рыжова 2016].

2 Исключение составляет Ставропольский край, где уровень доверия среди нерусских жителей региона снижен до $28 \%$ (среди русских он находится на среднем уровне в $47 \%$ ), что свидетельствует о непростой этнополитической ситуации в регионе, психологической напряженности, последствиях чрезвычайных ситуаций [Авксентьев, Шульга 2016].
} 
не доверяющих - 49\%. В Калининградской обл. это соотношение составляет $66 \%$ и 56\%, в Московской агломерации $-48 \%$ и $41 \%$, в Карелии $-71 \%$ и $61 \%$; в Татарстане прослеживается та же тенденция. В республиках России, где этничность имеет институциональный статус и активно проявлена в повседневных взаимодействиях, активным фактором общероссийской солидарности и межнационального согласия выступает высокий уровень межэтнического и межконфессионального доверия [Межнациональное согласие... 2016].

Таким образом, многолетние социологические исследования дают основания считать, что в современной интегрирующей российской идентичности силен уровень традиционных связей интеграции. Этническая идентичность/солидарность, доверие и установки межэтнической толерантности выступают в качестве значимых социокультурных и мировоззренческих основ формирующейся российской идентичности. Обобщенное доверие и межэтническая толерантность выполняют функции устойчивых опор межкультурной интеграции, а этническая идентичность русского большинства непосредственно вовлекается в формирование интегрирующей российской идентичности. Социокультурный базис российской идентичности необходимо усиливать политическими категориями самоопределения, в числе которых - правовое равенство, уважение к закону, которые приобретают вес вместе с развитием гражданского общества и устойчивых традиций политического участия.

\section{Список литературы}

Авксентьев В., Шульга М. 2016. Ставрополье: проблемы, риски, прогнозы. Вестник российской нации. № 1. С. 171-186.

Бызов Л.Г. 2012. Социокультурные и социально-политические аспекты формирования современной российской нации. - Полис. Политические исследования. № 4. С. 41-55.

Горшков М.К. 2013. Российская идентичность в контексте западноевропейской культуры. - Власть. № 1. С. 9-14.

Дробижева Л.М. 2018. Российская идентичность: дискуссии в политическом пространстве и динамика массового сознания. - Полис. Политические исследования. № 5. С. 100-115.

Дробижева Л.М., Рыжова С.В. 2015. Гражданская и этническая идентичность и образ желаемого государства в России. - Полис. Политические исследования. № 5. С. 9-24.

Межнациональное согласие как ресурс консолидации российского общества (отв. ред. Л.М. Дробижева). 2016. М.: Институт социологии РАН. 400 с.

Паин Э.А., Федюнин С.Ю. 2018. Проблемы гражданской нации в России и на Западе: общее и особенное. - Политическая концептология. № 1. С. 171-191.

Пантин В.И. 2011. Национально-цивилизационная идентичность: специфика России. - Политическая экспертиза: Политэкс. Т. 7. № 2. С. 42-51.

Российское общество и вызовы времени: монография (под ред. М.К. Горшкова, В.В. Петухова). Книга вторая. 2015. М.: Весь Мир. 432 с.

Рыжова С.В. 2011. Этническая идентичность в контексте толерантности. М.: Альфа-М. 280 с.

Рыжова С.В. 2016. Доверие и этническая толерантность в условиях социальных перемен. - Социологический журнал. Т. 22. № 1. С. 72-94.

Семененко И.С. 2015. Нация, национализм, национальная идентичность: новые ракурсы научного дискурса. - Мировая экономика и международные отношения. № 11. С. 91-102.

Тишков В.А. 2008-2016. Национальная идентичность (о смысле дебатов). - 
Вестник российской нации. Избранные труды академика РАН В.А. Тишкова о российской нации. Спецвыпуск № 51. С. 33-43.

Фукуяма Ф. 2006. Доверие: социальные добродетели и путь к процветанию (пер. с англ. Д. Павловой, В. Кирющенко, М. Колопотина). М.: АСТ Москва; Хранитель. 730 с.

Putnam R.D. 2001. Bowling Alone: The Collapse and Revival of American Community. N.Y., London, Toronto, Sydney: Simon and Schuster. 541 p.

Smith A. 1986. The Ethnic Origins of Nations. Oxford: Blackwell. 332 p.

RYZHOVA Svetlana Valentinovna, Cand.Sci. (Soc.), Leading Research Fellow of Sociological Institute - Branch of the Federal Center of Theoretical and Applied Sociology, Russian Academy of Sciences (bld. 5, 24/35 Krzhizhanovskogo St, Moscow, Russia, 117218; Silica2@yandex.ru)

\title{
ABOUT SOCIO-CULTURAL FOUNDATIONS OF THE RUSSIA'S CIVIL IDENTITY
}

\begin{abstract}
The article summarizes the results of sociological surveys of all-Russian and ethnic identity. The author concludes that in conditions of relative weakness of civil structures and political culture of participation, all-Russian identity is based on a wide range of socio-cultural sources. Ethnic identity and culture of trust play an important role among them. All-Russian and ethnic identities (mainly ethnic identity of Russians as the majority of the country) mutually support and nourish each other. Emotional involvement and the inspiring impulse of the state-civil Russian identity are provided and supported by the participation of feelings, perceptions, motivations that are part of the ethnic (ethnocultural) identity complex. Attitudes of interethnic tolerance act as a connecting link between the processes of strengthening ethnic identity and the formation of state-civil identity. Generalized trust (to people in general) and to people you know (to neighbors, colleagues, friends), as well as the skills of interethnic tolerance, can make a great contribution to the formation of national civil unity. These components form a bridging social capital (according to R. Putnam), aimed at involving all citizens of the country into a single field of civil integration. An important conclusion of the research is that generalized trust in all studied regions favors the formation of an all-Russian identity and interethnic tolerance. The sociocultural basis of all-Russian identity must be strengthened by political categories of self-determination, including legal equality and respect for the law, which gain weight along with the development of civil society and stable traditions of political participation.
\end{abstract}

Keywords: all-Russian identity, ethnic identity, trust, interethnic tolerance, socio-cultural foundations 